\title{
Is diabetes mellitus complicated by ketoacidosis in the elderly always latent autoimmune diabetes of the adult?
}

\section{Introduction}

Diabetic Ketoacidosis (DKA) which is seen usually in Type 1, latent autoimmune diabetes of the adult (LADA) and rarely in Type 2 Diabetes Mellitus (DM) is a acute complication. ${ }^{1,2}$ It is the cause of $50 \%$ of hospital admissions due to diabetes in young patients and also $1-2 \%$ of all diabetic hospital admissions. According to United States database, the annual incidence of DKA is 4.6-8 episodes per 1000 diabetic patients. The mortality rate in developed countries is reported to be between $2-10 \%$. There is $20 \%$ mortality over 65 years age.

\section{Case I}

66year-old female patient was admitted with confused concious and impaired orientation. Vital signs in the initial evaluation of the patient were as follows. TA: $100 / 70 \mathrm{~mm} \mathrm{Hg}$, respiratory rate $28 / \mathrm{min}$, heart rate $124 / \mathrm{min}$, fever $38.4 \mathrm{C}$. Upon admission, blood glucose was determined as $651 \mathrm{mg} / \mathrm{dl}$ in the emergency department. Arterial blood gas analysis was consistent with metabolic acidosis with increased anion gap. The patient's urine analysis was evaluated as ketone positive. She was diagnosed as pneumosepsis (confirmed by physical examination, blood and sputum cultures) and diabetic ketoacidosis. The patient was treated with diabetic ketoacidosis treatment protocol. The patient had history of hypertension, but no history of DM in either herself or her family. Her height, weight, BMI were $160 \mathrm{~cm}, 75 \mathrm{~kg}$, BMI $29.3 \mathrm{~kg} / \mathrm{m}^{2}$, respectively. The patient's $\mathrm{HbA1c}$ was determined as $10.5 \%$. C-peptide level of the patient was lower than normal $(1.8 \mathrm{ng} / \mathrm{ml})$, the antibody was negative. Treatment was regulated with diet and frequent intermittent subcutaneous insulin therapy. She was considered to be diabetic ketoacidosis diagnosed firstly as hyperglycemic crisis. ${ }^{3-5}$

\section{Case 2}

80year-old male patient was admitted to our emergency department with confused conscious. The patient's vital signs were stable. The blood glucose level was measured as $718 \mathrm{mg} / \mathrm{dL}$, urinalysis was ketone positive,arterial blood gas analysis was as follows : $\mathrm{pH}$ 7.01, pCO2 $20.4 \mathrm{mmHg}, \mathrm{HCO} 3: 5 \mathrm{mmol} / \mathrm{L}, \mathrm{Na}: 137 \mathrm{mmol} / \mathrm{L}, \mathrm{Cl}:$ $107 \mathrm{mmol} / \mathrm{L}$. The patient was treated as diabetic ketoacidosis and urinary tract infection. He had HbAlc level of $10.4 \%$, C-peptide $<12: 10 \mathrm{ng} / \mathrm{ml}$, islet cell antibody positive (1:32), anti GAD $>2000 \mathrm{IU} /$ $\mathrm{ml}(<10)$, insulin antibody $40.62 \%$ positive. The patient who were diagnosed at 65years age and followed for $15 y$ ears was hospitalized to the clinic with diabetic ketoacidosis. He was evaluated as LADA due to the positive antibodies.

\section{Discussion}

DKA can be seen in the elderly, whether autoimmune DM or not. Along with insulin deficiency, elevated catecholamine activates cortisol and growth hormone sensitive lipase and causes the

\author{
Volume 3 Issue 4 - 2016
}

\author{
Bahar Ozdemir,' Betul Erismis,' Hakan \\ Kocoglu, 'Yıldız Okuturlar,' Didem Acarer,' \\ Tarık Ercan,' Mehmet Hursitoglu,' Ozlem \\ Harmankaya,' Meral Mert ${ }^{2}$ \\ 'İnternal Medicine, Bakırkoy Dr. Sadi Konuk Training and \\ Research Hospital,Turkey \\ ${ }^{2}$ Endocrinology, Bakırkoy Dr. Sadi Konuk Training and Research \\ Hospital,Turkey
}

Correspondence: Meral Mert, Bakırkoy Dr. Sadi Konuk Training and Research Hospital, Istanbul,Turkey, Tel +902 124 147 171, Email meralmert@hotmail.com

Received: June 10,2016 | Published: July 06, 2016

destruction of triglycerides and the release of free fatty acids. They are used for making ketone bodies, beta-hydroxy butyric acid and acetoacetic acid. Acetoacetate is converted to acetone with nonenzymatic decarboxylation and ketone bodies produced are partly excreted in urine. At physiological $\mathrm{pH}$, ketoacids are separated and increased hydrogen ions reduce serum bicarbonate levels by connecting bicarbonate. Ketone bodies with in the form of anions in circulation increase anion gap. Metabolic acidosis with increased anion gap occurs with reduced bicarbonate level. The mortality rate increases with age in DKA, while the rate is $10 \%$ under 75 years of age, $19 \%$ between $79-84$ years of age and reaches $35 \%$ over 85 years. There is no difference in DKA treatment according to age. It is an acute complication of diabetes regardless of age. Autoimmune diabetes should be kept in mind in the differential diagnosis, while assessing each patient.

\section{Acknowledgements}

None.

\section{Conflict of interest}

Author declares that there is no conflict of interest.

\section{References}

1. Karin A Selva, Susan Marie Scott. Diabetic ketoacidosis associated with olanzapine in an adolescent patient. The Journal of Pediatrics. 2001;138(6):936-938.

2. Miriam F Delaney, Ariel Zisman, William M Kettyle. Acute Complications Of Diabetes: Diabetic Ketoacidosis And Hyperglycemic Hyperosmolar Nonketotic Syndrome. Endocrinology and Metabolism Clinics. 2000;29(4):683-705.

3. Goldman L, Ausiel D. Cecil medicine 23rd ed. 2007. 
4. Chiasson JL, Aris-Jilwan N, Bélanger R, et al. Diagnosis and treatment of diabetic ketoacidosis and the hyperglycemic hyperosmolar state. CMAJ. 2003;168(7):859-866.
5. Trence DL, Hirsch IB. Hyperglycemic crises in diabetes mellitus Type 2. Endocrinology and Metabolism Clinics. 2001;30(4):817-31. 